\title{
Are There Mobile Applications Related to Nail Disorders?
}

\author{
Stephanie Ishack, PhD; Shari R. Lipner, MD, PhD
}

\section{PRACTICE POINTS}

- Patient-targeted mobile applications (apps) might aid with clinical referencing and education.

- There are patient-directed psoriasis and hair loss apps on iOS and Android platforms, but informative apps related to nail disorders are limited.

- There is a need to develop apps related to nail health for patient education.

The role of mobile applications (apps) for patient education is expanding, with little inquiry evaluating the quantity and quality of nail disorder apps. Our objective was to investigate iOS (Apple's iPhone Operating System) and Android apps to determine the types of nail health apps that are available for patient education. A standard app analytics and market data tool was used to search and analyze iOS and Android nail apps for several nail health, psoriasis, and hair loss keywords.

Cutis. 2021;107:153-156.

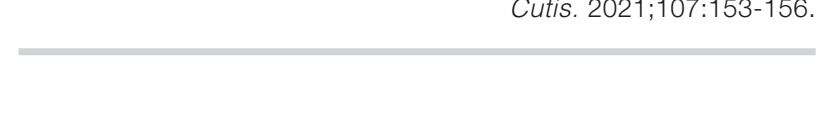

$\Gamma$ he use of mobile devices in health care settings has enhanced clinical practice through real-time communication and direct patient monitoring. ${ }^{1}$ With advancements in technology, improving the accessibility and quality of patient care using mobile devices is a hot topic. In 2018, 261.34 million people worldwide used smartphones compared to 280.54 million in 2021a $7.3 \%$ increase. $^{2}$ Revenue from sales of mobile applications (apps) is projected to reach $\$ 693$ billion in $2021 .^{3}$
A range of apps targeted to patients is available for acne, melanoma, and teledermatology. ${ }^{4-6}$ Nail disorders are a common concern, representing 21.1 million outpatient visits in 2007 to $2016,{ }^{7}$ but, to date, the availability of apps related to nail disorders has not been explored. In this study, we investigated iOS (Apple's iPhone Operating System) and Android apps to determine the types of nail health apps that are available, using psoriasis and hair loss apps as comparator groups.

\section{Methods}

A standard app analytics and market data tool (App Annie; https://www.appannie.com/en/) was utilized to search for iOS and Android nail mobile apps., ${ }^{4,5}$ The analysis was performed on a single day (March 23, 2020), given that app searches can change on a daily basis. Our search included the following keywords: nail, nail health, toenail fungus, nail tumor, brittle nails, onychomycosis, onycholysis, subungual melanoma, nail melanoma, paronychia, and nail squamous cell carcinoma. App Annie app descriptions were assessed to determine the type of each app (Lifestyle, Medical, Health \& Fitness) and target audience (patient, physician, or both). Psoriasis and hair loss topics were chosen as controls for comparison, based on a prior study. ${ }^{8}$ For psoriasis, the keywords psoriasis and chronic skin disease were searched. Hair loss was searched using the keywords alopecia, hair loss, hair health, and scalp.

\section{Results}

Nail-Related Apps-Using keywords for nail-related terms on $\mathrm{iOS}$ and Android platforms, our search returned few

Dr. Ishack is from the New York University School of Medicine, New York. Dr. Lipner is from the Department of Dermatology, Weill Cornell Medicine, New York.

The authors report no conflict of interest.

Correspondence: Shari R. Lipner MD, PhD, 1305 York Ave, New York, NY 10021 (shl9032@med.cornell.edu).

doi: $10.12788 /$ cutis.0198 
specific and informative apps related to nail disorders (Table 1). When the terms brittle nails, nail, nail health, nail squamous cell carcinoma, and nail tumor were searched, all available nail apps were either nail games or virtual nail salons for entertainment purposes. For the terms nail melanoma and subungual melanoma, there were no specific nail apps that appeared in the search results; rather, the App Annie search yielded only general dermatology and melanoma apps. The terms onycholysis and paronychia both yielded 0 hits for iOS and Android.

The only search terms that returned specific nail apps were onychomycosis and toenail fungus. Initially, when onychomycosis was searched, only 1 Google Play Medical category app was found: "Nail fungal infection (model onychomycosis)." Although this app recently was removed from the app store, it previously allowed the user to upload a nail photograph, with which a computing algorithm assessed whether the presentation was a fungal nail infection. Toenail fungus returned $1 \mathrm{iOS}$ Medical category app and 5 Android Health \& Fitness category apps with reference material for patients. Neither of the 2 medical apps for onychomycosis and toenail fungus referenced a physician involved in the app development.

Psoriasis Comparator-On the contrary, a search for psoriasis yielded 22 hits for iOS and 34 hits for Android within the Health \& Fitness, Medical, and Social Networking categories (Table 2). The search term chronic skin disease returned 18 apps for iOS and 60 apps for
Android related to psoriasis; $100 \%$ were classified as Medical apps.

Hair Loss Comparator-Search terms related to hair conditions-specifically, alopecia-yielded 0 apps for iOS and 10 for Android platforms (Table 2). Using the search term hair loss, 12 apps for iOS and 50 apps for Android were found within the Health \& Fitness, Medical, and Beauty categories. The search terms hair health and hair loss resulted in 2 and 12 apps in both iOS and Android, respectively. In addition, the search term scalp was associated with 6 related apps in iOS and 7 in Android, both in the Health \& Fitness and Medical categories.

Other Findings-Most apps for psoriasis and hair health were identified as patient focused. Although iOS and Android are different operating systems, some health apps overlapped: subungual melanoma and toenail fungus had a $20 \%$ overlap; psoriasis, $19 \%$; chronic skin disease, $2 \%$; alopecia, $0 \%$; hair loss and hair health, 10\%; and scalp, 18\%. iOS and Android nail entertainment games had approximately a $30 \%$ overlap. Tables 1 and 2 also compare the number of free and paid apps; most available apps were free.

\section{Comment}

With continued growth in mobile device ownership and app development has been parallel growth in the creation and use of apps to enhance medical care. ${ }^{1}$ In a study analyzing the most popular dermatology apps, 62\% (18/29) and $38 \%(11 / 29)$ of apps targeted patients and physicians, respectively. ${ }^{6}$ Our study showed that (1) there are few nail

\section{TABLE 1. App Annie Search Results for Nail-Related Applications (Apps) for iOS and Android}

\begin{tabular}{|c|c|c|c|c|c|}
\hline \multirow[b]{2}{*}{ Search term(s) } & \multirow[b]{2}{*}{ Total hits } & \multirow[b]{2}{*}{ Free/paid apps } & \multicolumn{2}{|c|}{ Android } & \multirow[b]{2}{*}{$\begin{array}{l}\text { Target } \\
\text { audience }\end{array}$} \\
\hline & & & Total hits & $\begin{array}{l}\text { Free/paid } \\
\text { apps }\end{array}$ & \\
\hline $\begin{array}{l}\text { Brittle nails, nail, nail } \\
\text { health, nail squamous } \\
\text { cell carcinoma, } \\
\text { nail tumor }\end{array}$ & $\begin{array}{l}600 \text { (100\% nail } \\
\text { game and nail salon } \\
\text { entertainment apps) }\end{array}$ & $583 / 17$ & $\begin{array}{l}600 \text { (100\% nail } \\
\text { game and nail salon } \\
\text { entertainment apps) }\end{array}$ & $588 / 12$ & General public \\
\hline $\begin{array}{l}\text { Nail melanoma, } \\
\text { subungual } \\
\text { melanoma }\end{array}$ & $\begin{array}{l}20 \text { (100\% Medical [general } \\
\text { dermatology, melanoma]) }\end{array}$ & $17 / 3$ & $\begin{array}{l}15 \text { (100\% Medical } \\
\text { [general dermatology, } \\
\text { melanoma]) }\end{array}$ & All free & General public \\
\hline Onychomycosis & 0 & NA & 1 (Medical) & Free & Patients \\
\hline Toenail fungus & $\begin{array}{l}4 \text { ( } 3 \text { nail game } \\
\text { entertainment apps, } \\
1 \text { Medical) }\end{array}$ & $3 / 1$ & $\begin{array}{l}15 \text { (10 nail game } \\
\text { entertainment apps, } \\
5 \text { Health \& Fitness) }\end{array}$ & $9 / 6$ & Patients \\
\hline $\begin{array}{l}\text { Onycholysis, } \\
\text { paronychia }\end{array}$ & 0 & NA & 0 & NA & NA \\
\hline
\end{tabular}

Abbreviation: NA, not applicable.

aData based on App Annie results from March 23, 2020. 
disorder apps available for patient education and (2) there is no evidence that a physician was consulted for content input. Because patients who can effectively communicate their health concerns before and after seeing a physician have better self-reported clinical outcomes, ${ }^{9}$ it is important to have nail disorder apps available to patients for referencing. The nail health app options differ notably from psoriasis and hair loss apps, with apps for the latter 2 topics found in Medical and Health \& Fitness categories-targeting patients who seek immediate access to health care and education.

Although there are several general dermatology apps that contain reference information for patients pertaining to nail conditions, ${ }^{6}$ using any of those apps would require a patient to have prior knowledge that dermatologists specialize in nail disorders and necessitate several steps to find nail-relevant information. For example, the patient would have to search dermatology in the iOS and Android app stores, select the available app (eg, Dermatology Database), and then search within that app for nail disorders. Therefore, a patient who is concerned about a possible subungual melanoma would not be able to easily find clinical images and explanations using an app.

Study Limitations-This study was subject to several limitations. Android and iOS app stores have undisclosed computing algorithms that might have filtered apps based on specific word inquiry. Also, our queries were based on specific relevant keywords for nail conditions, psoriasis, and hair loss; use of different keywords might have yielded different results. Additionally, app options change on a daily basis, so a search today (ie, any given day) might yield slightly different results than it did on March 23, 2020.

\section{Conclusion}

Specific nail disorder apps available for patient reference are limited. App developers should consider accessibility (ie, clear language, ease of use, cost-effectiveness, usability on iOS- and Android-operated devices) and content (accurate medical information from experts) when considering new apps. A solution to this problem is for established medical organizations to create nail

TABLE 2. App Annie Search Results for Psoriasis-Related and Hair Loss Applications (Apps) for iOS and Android ${ }^{\mathrm{a}}$

\begin{tabular}{|c|c|c|c|c|c|}
\hline \multirow[b]{2}{*}{ Search term } & \multicolumn{2}{|l|}{ iOs } & \multicolumn{2}{|l|}{ Android } & \multirow[b]{2}{*}{ Target audience } \\
\hline & Total hits & $\begin{array}{l}\text { Free/paid } \\
\text { apps }\end{array}$ & Total hits & $\begin{array}{l}\text { Free/paid } \\
\text { apps }\end{array}$ & \\
\hline \multicolumn{6}{|c|}{ Psoriasis related } \\
\hline Psoriasis & $\begin{array}{l}22 \text { (17 Medical; } 2 \text { Health \& } \\
\text { Fitness; } 2 \text { Social Networking } \\
\text { 1 Reference) }\end{array}$ & $21 / 1$ & $\begin{array}{l}34 \text { (18 Health \& Fitness; } \\
10 \text { Medical; } \\
3 \text { Social Networking; } \\
3 \text { Reference) }\end{array}$ & $25 / 9$ & Patient education \\
\hline $\begin{array}{l}\text { Chronic skin } \\
\text { disease }\end{array}$ & $\begin{array}{l}600 \text { (18 related to skin } \\
\text { disease }[100 \% \text { Medical]) }\end{array}$ & $13 / 5$ & $\begin{array}{l}600 \text { (60 related to skin } \\
\text { disease }[100 \% \text { Medical]) }\end{array}$ & $58 / 2$ & Patient education \\
\hline Hair loss relate & & & & & \\
\hline Alopecia & 0 & NA & 10 (100\% Medical) & All free & NA \\
\hline Hair loss & $\begin{array}{l}600 \text { (12 related to hair loss } \\
{[7 \text { Health \& Fitness, } 5} \\
\text { Medical]) }\end{array}$ & $12 / 0$ & $\begin{array}{l}600 \text { (50 related to } \\
\text { hair loss [ } 45 \text { Health \& } \\
\text { Fitness, } 5 \text { Beauty]) }\end{array}$ & $48 / 2$ & Patient education \\
\hline Hair health & $\begin{array}{l}600 \text { ( } 2 \text { related to hair health } \\
{[1 \text { Health \& Fitness, }} \\
1 \text { Medical }])\end{array}$ & $2 / 0$ & $\begin{array}{l}600 \text { ( } 2 \text { related to hair } \\
\text { health [2 Beauty]) }\end{array}$ & $2 / 0$ & Patient education \\
\hline Scalp & $\begin{array}{l}9 \text { (6 related to scalp [3 } \\
\text { Health } \\
\text { \& Fitness, } 3 \text { Medical]) }\end{array}$ & $5 / 1$ & $\begin{array}{l}25 \text { (7 related to scalp } \\
{[6 \text { Health \& Fitness, }} \\
1 \text { Medical]) }\end{array}$ & $6 / 1$ & Patient education \\
\hline
\end{tabular}


disorder apps specifically for patients. ${ }^{10}$ For example, the American Academy of Dermatology has iOS and Android apps that are relevant to physicians (MyDermPath+, Dialogues in Dermatology, Mohs Surgery Appropriate Use Criteria) but no comparable apps for patients; patient-appropriate nail apps are necessary. ${ }^{11}$ In addition, it would be beneficial to patients if established app companies consulted with dermatologists on pertinent nail content.

In sum, we found few available nail health apps on the iOS or Android platforms that provided accessible and timely information to patients regarding nail disorders. There is an immediate need to produce apps related to nail health for appropriate patient education.

\section{REFERENCES}

1. Wallace S, Clark M, White J. 'It's on my iPhone': attitudes to the use of mobile computing devices in medical education, a mixed-methods study. BMJ Open. 2012;2:e001099.

2. O'Dea S. Number of smartphone users in the United States from 2018 to 2024 (in millions). Statista website. April 21, 2020. Accessed February 19, 2021. https://www.statista.com/statistics/201182 /forecast-of-smartphone-users-in-the-us/
3. Clement J. Worldwide mobile app revenues in 2014 to 2023. Statista website. Published February 4, 2021. Accessed February 19, 2021. https://www.statista.com/statistics/269025/worldwide-mobile -app-revenue-forecast/

4. Poushter J, Bishop C, Chwe H. Social media use continues to rise in developing countries but plateaus across developed ones. Pew Research Center Washington DC. Published June 19, 2018. Accessed February 19, 2021. https://www.pewresearch.org/global/2018/06/19/social-media -use-continues-to-rise-in-developing-countries-but-plateaus-across -developed-ones/

5. Flaten HK, St Claire C, Schlager E, et al. Growth of mobile applications in dermatology_2017 update. Dermatol Online J. 2018 February;24:1-4. Accessed February 19, 2021. https://escholarship.org/uc/item/3hs7n9z6

6. Tongdee E, Markowitz O. Mobile app rankings in dermatology. Cutis. 2018;102:252-256.

7. Lipner SR, Hancock J, Fleischer AB. The ambulatory care burden of nail conditions in the United States [published online October 21, 2019]. J Dermatol Treat. doi:10.1080/09546634.2019

8. Gu L, Lipner SR. Analysis of education on nail conditions at the American Academy of Dermatology annual meetings. Cutis. 2020;105:259-260.

9. King A, Hoppe RB. “Best practice” for patient-centered communication: a narrative review. J Grad Med Educ. 2013;3:385-393.

10. Larson RS. A path to better-quality mHealth apps. JMIR Mhealth Uhealth. 2018;6:E10414.

11. Academy apps. American Academy of Dermatology website. Accessed February 19, 2021. https://www.aad.org/member/publications/apps 